Bangladesh J. PI. Breed. Genet, 24(1): 27-32

\title{
VARIABILITY AND CHARACTER ASSOCIATION FOR REPRODUCTIVE TRAITS IN ONION (Allium cepa $\mathrm{L}$ )
}

\author{
M. S. Akter, N. A. Ivy, M. A. K. Mian and M. M. Hoque ${ }^{1}$ \\ Department of Genetics and Plant Breeding \\ Bangabandhu Sheikh Mujibur Rahman Agricultural University \\ Gazipur 1706, Bangladesh
}

\begin{abstract}
The experiment was conducted with the objective to study the variability and the character association for reproductive traits in exotic and local onion genotypes. Ten genotypes of onion (Allium cepa L) collected from different sources, namely; Indian medium $\left(\mathrm{G}_{1}\right)$, Indian medium $\left(\mathrm{G}_{2}\right)$, Indian small $\left(\mathrm{G}_{3}\right)$, Taherpuri $\left(\mathrm{G}_{4}\right)$, Patnai pink $\left(\mathrm{G}_{5}\right)$, Patnai small $\left(\mathrm{G}_{6}\right)$, Big single bulb $\left(\mathrm{G}_{7}\right)$, Big double bulb $\left(\mathrm{G}_{8}\right)$, Small single bulb $\left(\mathrm{G}_{9}\right)$, Small double bulb $\left(\mathrm{G}_{10}\right)$ were included in the study. Significant variations were observed among the genotypes for all the characters at $1 \%$ level except umbel diameter. This indicates that there is a wide genotypic variation among the genotypes for all the characters studied except umbel diameter. Considering genetic parameters, high GCV values were observed for days to $100 \%$ sprouting, number of unfilled seeds per umbel, number of filled seeds per umbel, number of flowers per umbel, number of seeds per umbel, number of seeds per plant and seed yield per umbel (gm). High heritability values with high genetic advances in percent of mean were obtained for days to $100 \%$ sprouting, days to $50 \%$ bolting, number of unfilled seeds per umbel and seed yield per umbel (gm). Correlation analysis indicated significant positive genotypic and phenotypic correlation coefficient of number of seeds per plant, 100 seed weight (gm), number of seeds per umbel and number of unfilled seeds per umbel with seed yield per umbel (gm). Number of flowers per umbel and number of filled seeds per umbel had the highest positive direct effect on seed yield (gm). Days to $100 \%$ sprouting, umbel diameter and number of seeds per plant had direct negative effect on seed yield. Path analysis exhibited that highly significant positive correlation with positive direct effect showed for number of filled seeds per umbel (1.87), number of flowers per umbel (1.52) and 100seed weight $(0.74 \mathrm{~g})$. Days to $50 \%$ bolting, number of seeds per plant, number of flowers per umbel, number of filled seeds per umbel, number of unfilled seeds per umbel and seed yield per umbel could be selected as yield contributing characters in onion.
\end{abstract}

Key words: GCV, PCV, heritability, correlation, path analysis, onion

\section{INTRODUCTION}

Onion (Allium cepa L., $2 \mathrm{n}=16$ ) is a bulb crop belonging to the family Alliaceae. It is a cross pollinated, seed propagated and biennial important spices as well as vegetable crop through out the world. The genus Allium consists of 500 species and onion (Allium cepa L) is the only cultivated species in this genus. It displays great

\footnotetext{
${ }^{1}$ Professor, Department of Agronomy, Bangabandhu Sheikh Mujibur Rahman Agricultural University, Gazipur 1706, Bangladesh
} 
morphological diversity in bulb and leaf size, color and shape, presence scale and plant height, flower color, fertility and bulbil (top set) development (Pooler and Simon, 1993). Central Asia is the primary center of its origin and the Mediterranean area is the secondary center for large type of onion (Mc. Collum, 1976). Increased onion production largely depends on good variety, modern production technology and quality seeds. Inferior seeds may decrease production by $15-25 \%$. Yield could be regarded as a complex character, which is dependent on a number of agronomic characters and is influenced by many factors, which could be genetic or environmental (Uddin et al., 1985). Path coefficient help to partition total correlation into direct and indirect components. In that case, it becomes necessary to partition the observed variability into heritable and non-heritable components with the help of suitable genetic parameters such as genetic coefficient of variation (GCV), heritability estimate and genetic advance. It is also beneficial to make a comparative variability and character association for reproductive traits to select the desirable ones in different genotypes. Study of characters association help to identify the role of each individual character towards yield. Due to shortage, large quantity of onion bulbs are importing every year from different countries. As a result various types of onion are available in the market. Therefore the present study has been taken to study variability and the character association for reproductive traits in exotic and local onion genotypes.

\section{METERIALS AND METHODS}

The research work was carried out at the experimental field of the Department of Genetics and Plant Breeding, Bangabandhu Sheikh Mujibur Rahman Agricultural University (BSMRAU), Gazipur during rabi season of 2008-2009. The experimental site was situated in the tropical climate zone. The location of the site was at $24.00^{\circ} \mathrm{N}$ latitude and $90.25^{\circ} \mathrm{E}$ longitudes with and elevation of 8.4 meter from sea level. The soil of the experimental field was sandy loam in texture having a $\mathrm{pH}$ of around 6.5. The land was high with uniform topography and almost homogenous with respect to soil fertility. The material comprised of ten genotypes of onion (Allium cepa L.) including one check variety, Taherpuri which is given in Table-1. The experiment was laid out in a randomized complete block design (RCBD) with three replications. The field was divided into three blocks. The blocks were subdivided into ten plots where genotypes assigned randomly. The unit plot size was $4 \mathrm{~m} \times 2 \mathrm{~m}$ consisting of four row of each genotype. Row to row distance was $50 \mathrm{~cm}$ and plant to plant distance was $20 \mathrm{~cm}$. The experimental plot was prepared by deep ploughing followed by harrowing and laddering. The recommended doses of fertilizers viz cow dung, Urea, TSP and MP @ 10t, 130kg, $200 \mathrm{~kg}, 75 \mathrm{~kg}$ per ha, respectively were applied in the experimental field. The entire cowdung, TSP, half of urea and half of MP were applied at the time of final land preparation. The remaining urea and MP were applied as top dressing in two installments. Immediately after germination, the straws were removed and weeding was done properly. Frequent irrigation was applied in plot as per requirements of the bulb. Rovral was applied two times at seven days interval after bulb sowing to control Alternaria leaf blight. No insecticides were used in the experimental plot. Data were recorded for days to $100 \%$ sprouting (DS), days to $50 \%$ bolting (DB), length of stalk (LS) , umbel diameter (UD), percent of fertile pollen (FP), number of flowers per umbel (NFU),100 seed weight (SW), number of seeds per umbel (NSU), number of seeds per plant (NSP), number of filled seeds per umbel (NFSU), number of unfilled seeds per umbel (NUSU) and seed yield per umbel (SYU). 
Table 1.Name and sources of collection of onion genotypes used for the experiment

\begin{tabular}{c|l|l|l}
\hline Genotype No. & Genotypes & Source of collection & Country of Origin \\
\hline $\mathrm{G}_{1}$ & Indian big & Local market & India \\
$\mathrm{G}_{2}$ & Indian medium & Local market & India \\
$\mathrm{G}_{3}$ & Indian small & Local market & India \\
$\mathrm{G}_{4}$ & Taherpuri & Rajshai & Bangladesh \\
$\mathrm{G}_{5}$ & Patnai pink & Local market & India \\
$\mathrm{G}_{6}$ & Patnai small & Local market & India \\
$\mathrm{G}_{7}$ & Big single bulb & BSMRAU & Bangladesh \\
$\mathrm{G}_{8}$ & Big double bulb & BSMRAU & Bangladesh \\
$\mathrm{G}_{9}$ & Small single bulb & BSMRAU & Bangladesh \\
$\mathrm{G}_{10}$ & Small double bulb & BSMRAU & Bangladesh \\
\hline
\end{tabular}

\section{Results and Discussion}

The analysis of variance (ANOVA), mean, range, genotypic and phenotypic variances, genotypic and phenotypic coefficient of variations, broad sense heritability, genetic advance, genetic advance in percent of mean of the related characters are presented in Table 2 . The analysis of variance showed highly significant variation at $1 \%$ level of different characters except umbel diameter among the genotypes. Significant differences for genetic variability, heritability and genetic advance were observed among the genotypes for all the characters at $1 \%$ level except umbel diameter. Genotype $\mathrm{G}_{7}$ $(167.28 \mathrm{~g})$ produced the highest yield and the lowest yield was produced by $\mathrm{G}_{10}(32.40 \mathrm{~g})$. Genotypic coefficient of variation (GCV) was close to phenotypic coefficient of variation for most of the characters except umbel diameter and days to $100 \%$ sprouting suggested that the expression of these characters were mostly under the control of genotype and less influenced of environment. So it indicated a bright scope of selection of high yielding genotypes. High heritability $(>50 \%)$ was observed for all the characters except umbel diameter. Considerable genetic advance was also observed for days to $50 \%$ bolting, number of flowers per umbel and number of filled seeds per umbel. Extreme genetic advance was observed for days to $100 \%$ sprouting, number of unfilled seeds per umbel and seed yield per umbel. High heritability (99.99) coupled moderate genetic advance (24.84) in percent of mean for number of filled seed per umbel indicated that selection would not be effective. Whereas, low heritability and low genetic advance was found for the trait umbel diameter which made difficult to predict on the expected improvement through selection.

Table 2. Estimation of genetic components of 12 yield related characters in onion

\begin{tabular}{lcccc|ccc}
\hline Component & DS & DB & LS & FP & UD & NSP \\
\hline Range & $19.00-$ & $65.00-$ & $68.04-$ & $95.17-$ & $41.65-$ & $1255.00-$ \\
& 10.33 & 43.00 & 58.96 & 83.62 & 36.86 & 391.00 \\
Mean & 14.27 & 49.33 & 61.73 & 90.93 & 38.54 & 987.33 \\
$\sigma^{2} \mathrm{~g}$ & 10.46 & 100.78 & 11.55 & 23.51 & 2.26 & 93618.57 \\
$\sigma_{\mathrm{p}}^{2}$ & 12.08 & 101.34 & 11.95 & 24.10 & 4.48 & 93852.83 \\
$\mathrm{GCV}$ & 22.65 & 17.66 & 5.51 & 5.33 & 3.90 & 30.73 \\
$\mathrm{PCV}$ & 24.34 & 17.71 & 5.60 & 5.50 & 5.49 & 30.77 \\
$\mathrm{~h}_{\mathrm{b}}^{2}$ & 86.57 & 99.44 & 96.68 & 94.07 & 50.39 & 99.75 \\
$\mathrm{GA}(5 \%)$ & 43.41 & 36.29 & 11.15 & 10.65 & 5.70 & 63.22 \\
$\mathrm{GA} \%$ mean & 303.97 & 63.85 & 18.65 & 11.72 & 14.79 & 6.34 \\
F-Test & $* *$ & $* *$ & $* *$ & $* *$ & $*$ & $* *$ \\
CV\% & 8.92 & 1.32 & 1.02 & 1.34 & 3.87 & 1.54 \\
\hline
\end{tabular}




\begin{tabular}{|c|c|c|c|c|c|c|}
\hline Component & SW & NFU & NSU & NFSU & NUSU & SYU \\
\hline Range & $\begin{array}{c}0.38- \\
0.38\end{array}$ & $\begin{array}{c}287.00- \\
141.00\end{array}$ & $\begin{array}{c}479.00- \\
223.00\end{array}$ & $\begin{array}{c}421.00- \\
68.73\end{array}$ & $\begin{array}{c}167.00- \\
32.00\end{array}$ & $\begin{array}{l}1.30- \\
0.38\end{array}$ \\
\hline Mean & 0.32 & 172.93 & 290.36 & 331.29 & 59.50 & 1.04 \\
\hline$\sigma_{g}^{2}$ & 0.003 & 3148.56 & 8081.65 & 17511.92 & 2814.97 & 0.11 \\
\hline$\sigma_{p}^{2}$ & 0.003 & 3149.77 & 8082.81 & 17512.95 & 2823.400 & 0.11 \\
\hline GCV & 17.30 & 32.47 & 23.03 & 39.95 & 89.19 & 33.07 \\
\hline PCV & 17.32 & 32.47 & 23.03 & 39.95 & 89.32 & 33.11 \\
\hline $\mathrm{h}_{\mathrm{b}}^{2}$ & 99.75 & 99.96 & 99.99 & 99.99 & 99.70 & 99.78 \\
\hline GA $(5 \%)$ & 35.59 & 66.87 & 47.44 & 82.28 & 183.45 & 68.06 \\
\hline GA\% mean & 11.12 & 38.69 & 12.15 & 24.84 & 308.37 & 6607.57 \\
\hline F-Test & $* *$ & $* *$ & $* *$ & $* *$ & ** & $* *$ \\
\hline CV\% & 0.87 & 0.63 & 0.28 & 0.31 & 4.88 & 1.56 \\
\hline
\end{tabular}

Legend
$\sigma^{2} \mathrm{~g}=$ Genotypic variance, $\sigma^{2} \mathrm{p}=$ Phenotypic variance, $\mathrm{h}^{2} \mathrm{~b}=$ Heritability, GA=Genetic advance, GCV=Genotypic Coefficients of Variations, PCV=Phenotypic Coefficients of Variations, DS = Days to $100 \%$ sprouting, DB = Days to $50 \%$ bolting, LS=Length of stalk, FP=Percent of fertile pollen, UD =Umbel diameter, NSP $=$ Number of seeds per plant, $\mathrm{SW}=100$-seed weight, NFU =Number of flowers per umbel, NSU = Number of seeds per umbel, NFSU $=$ Number of filled seeds per umbel, NUSU $=$ Number of unfilled seeds per umbel and SYU $=$ seed yield per umbel.

\section{Correlation study}

The correlation coefficients were determined to find out the inter relationship among the characters studied. Phenotypic and genotypic correlation coefficient between yield and its eleven component characters are presented in Table 3.

Table 3. Phenotypic $\left(r_{p}\right)$ and genotypic $\left(r_{g}\right)$ correlation coefficients among the yield and yield related characters of onion

\begin{tabular}{|c|c|c|c|c|c|c|c|c|c|c|c|c|}
\hline Parameter & & DB & LS & FP & UD & NSP & SW & NFU & NSU & NFSU & NUSU & SYU \\
\hline \multirow[t]{2}{*}{ DS } & $r_{g}$ & $\begin{array}{l}-0.03 \\
\end{array}$ & -0.76 & 0.15 & -0.73 & -0.09 & 0.20 & 0.04 & 0.04 & 0.05 & 0.11 & 0.02 \\
\hline & $r_{p}$ & -0.05 & -0.66 & 0.18 & -0.50 & -0.08 & 0.19 & 0.04 & 0.14 & -0.05 & 0.10 & 0.02 \\
\hline \multirow[t]{2}{*}{ DB } & $r_{g}$ & & 0.17 & 0.30 & 0.33 & -0.52 & -0.17 & 0.37 & -0.11 & -0.67 & 0.37 & -0.49 \\
\hline & $\mathrm{r}_{\mathrm{p}}$ & & 0.16 & 0.29 & 0.24 & -0.52 & -0.17 & 0.37 & -0.44 & -0.57 & 0.37 & -0.48 \\
\hline \multirow[t]{2}{*}{ LS } & $r_{g}$ & & & 0.43 & 0.78 & 0.31 & 0.10 & -0.46 & 0.02 & 0.37 & -0.49 & 0.17 \\
\hline & $r_{p}^{g}$ & & & 0.42 & 0.64 & 0.31 & 0.10 & -0.46 & 0.07 & 0.36 & -0.47 & 0.17 \\
\hline \multirow[t]{2}{*}{ FP } & $r_{g}$ & & & & -0.12 & 0.59 & 0.77 & -0.76 & 0.15 & 0.58 & -0.74 & 0.59 \\
\hline & $r_{p}$ & & & & -0.05 & 0.57 & 0.75 & -0.73 & 0.58 & 0.56 & -0.71 & 0.57 \\
\hline \multirow[t]{2}{*}{ UD } & $r_{g}$ & & & & & -0.36 & -0.68 & 0.16 & -0.13 & -0.18 & 0.19 & -0.49 \\
\hline & $r_{p}$ & & & & & -0.24 & -0.47 & 0.11 & -0.36 & -0.13 & 0.14 & -0.34 \\
\hline \multirow[t]{2}{*}{ NSP } & $r_{g}$ & & & & & & $0.85^{*}$ & $-0.95^{* *}$ & 0.24 & $0.96 * *$ & $-0.96 * *$ & $0.99 * *$ \\
\hline & $r_{p}$ & & & & & & $0.85^{*}$ & -0.95 & $0.94 * *$ & $0.96 * *$ & $-0.96 * *$ & $0.98 * *$ \\
\hline \multirow[t]{2}{*}{ SW } & $r_{g}$ & & & & & & & $-0.82 *$ & 0.22 & 0.74 & $-0.85^{*}$ & $0.89^{*}$ \\
\hline & $r_{p}$ & & & & & & & $-0.82 *$ & $0.86^{*}$ & 0.74 & $-0.84 * *$ & $0.89^{*}$ \\
\hline \multirow[t]{2}{*}{ NFU } & $r_{g}$ & & & & & & & & -0.23 & $-0.97 * *$ & $0.99^{* *}$ & $-0.91 *$ \\
\hline & $r_{p}$ & & & & & & & & $-0.83^{*}$ & $-0.97 * *$ & $0.99^{* *}$ & $-0.91 *$ \\
\hline \multirow[t]{2}{*}{ NSU } & $r_{g}$ & & & & & & & & & $0.91 *$ & $-0.87 * *$ & $0.98 * *$ \\
\hline & $r_{p}$ & & & & & & & & & $0.91 *$ & $-0.87 *$ & $0.98 * *$ \\
\hline \multirow[t]{2}{*}{ NFSU } & $\mathrm{rg}$ & & & & & & & & & & $-0.96 * *$ & $0.93 * *$ \\
\hline & $r_{p}$ & & & & & & & & & & $-0.96 * *$ & $0.93 * *$ \\
\hline \multirow[t]{2}{*}{ NUSU } & $r_{g}$ & & & & & & & & & & & $-0.92 * *$ \\
\hline & $r_{p}$ & & & & & & & & & & & $-0.92 * *$ \\
\hline
\end{tabular}

Legend

rg indicates genotypic correlation coefficient and rp indicates phenotypic correlation coefficient DS $=$ Days to $100 \%$ sprouting, DB $=$ Days to $50 \%$ bolting, LS $=$ Length of stalk, FP $=$ Percent of fertile pollen, UD $=$ Umbel diameter, NSP $=$ Number of seeds per plant, $\mathrm{SW}=100$-seed weight, $\mathrm{NFU}=$ Number of flowers per umbel, NSU $=$ Number of seeds per umbel, NFSU $=$ Number of filled seeds per umbel, NUSU $=$ Number of unfilled seeds per umbel and SYU $=$ seed yield per umbel.,* indicates significant at $5 \%$ level, $* *$ indicates significant at $1 \%$ level. 
In most of the cases genotypic correlation coefficients were higher than phenotypic correlation coefficients indicating the association was largely due to genetic reason. In some cases phenotypic correlation coefficients were same or higher than genotypic correlation coefficients suggesting that both environmental and genotypic correlation in these cases acted in the same direction and finally maximize their expression at phenotypic level. Correlation analysis indicated significant positive genotypic and phenotypic correlation coefficient of number of seeds per plant, 100 seed weight (gm), number of seeds per umbel and number of unfilled seeds per umbel with seed yield (gm). So selection would be effective for improving seed yield per plant in onion by selecting the characters number of seeds per plant, 100 seed weight (gm), number of seeds per umbel and number of unfilled seeds per umbel with seed yield (gm) Table 3. Mohanty ( 2001), Aliyu et al. (2007) and Rahman et al. (2002) also reported that number of leaves per plant was positively correlated with bulb yield as well as plant height, Singh and Tiwari (1995) stated that functional leaves per plant had strong positive significant correlation with bulb weight, bulb diameter and bulb girth. Singh (1987) carried out trial for genotypic and phenotypic correlation and path analysis among bulb yield and its components for two years trial on nine cultivars of garlic which are similar to present findings.

\section{Path analysis}

In order to obtain a clear picture of the inter relationship between seed yield and other yield components, direct and indirect effects were worked out using path analysis. The results are presented in Table 4. The results had significant positive correlation with positive direct effect showed for number of filled seeds per umbel (1.87), number of flowers per umbel (1.52) and 100 seed weight $(0.74 \mathrm{~g})$. Path analysis revealed that days to $100 \%$ sprouting had negative direct effect on seed yield.

Table 4. Path coefficient showing direct (bold value) and indirect effects of yield and yield related characters on bulb yield of onion

\begin{tabular}{l|c|c|c|c|c|c|c|c|c|c|c|c}
\hline $\begin{array}{c}\text { Compo- } \\
\text { nents }\end{array}$ & DS & DB & LS & FP & UD & NSP & SW & NFU & NSU & NFSU & NUSU & $\begin{array}{c}\text { Yield } \\
(\mathrm{gm} / \\
\text { umbel })\end{array}$ \\
\hline DS & $\mathbf{- 0 . 1 2}$ & -0.00 & -0.10 & 0.00 & 0.03 & 0.01 & 0.145 & 0.07 & 0.04 & -0.09 & 0.02 & 0.02 \\
DB & 0.00 & $\mathbf{0 . 0 9}$ & 0.00 & 0.02 & -0.02 & 0.07 & -0.124 & 0.56 & -0.11 & -1.06 & 0.06 & -0.49 \\
LS & 0.08 & 0.02 & $\mathbf{0 . 1 3}$ & 0.02 & -0.03 & -0.04 & 0.072 & -0.71 & 0.02 & 0.69 & -0.08 & 0.17 \\
FP & -0.02 & 0.03 & 0.06 & $\mathbf{0 . 0 5}$ & 0.01 & -0.08 & 0.575 & -1.15 & 0.15 & 1.08 & -0.12 & 0.59 \\
UD & 0.08 & 0.03 & 0.10 & -0.01 & $\mathbf{- 0 . 0 4}$ & 0.05 & -0.508 & 0.24 & -0.12 & -0.34 & 0.03 & -0.50 \\
NSP & 0.01 & -0.05 & 0.04 & 0.03 & 0.02 & $\mathbf{- 0 . 1 3}$ & 0.633 & -1.45 & 0.24 & 1.80 & -0.16 & $0.99^{* *}$ \\
SW & -0.02 & -0.02 & 0.01 & 0.04 & 0.03 & -0.11 & $\mathbf{0 . 7 4 3}$ & -1.25 & 0.22 & 1.38 & -0.14 & $0.89^{*}$ \\
NFU & -0.00 & 0.03 & 0.06 & 0.04 & -0.01 & 0.13 & -0.612 & $\mathbf{1 . 5 2}$ & -0.23 & 1.81 & 0.16 & -0.19 \\
NSU & -0.02 & -0.04 & 0.01 & 0.03 & 0.02 & -0.13 & 0.639 & -1.35 & $\mathbf{0 . 2 6}$ & 1.69 & -0.14 & $0.98^{* *}$ \\
NFSU & 0.01 & -0.05 & 0.05 & 0.03 & 0.01 & -0.13 & 0.550 & -1.48 & 0.23 & $\mathbf{1 . 8 7}$ & -0.16 & $0.93^{* *}$ \\
NUSU & -0.01 & 0.03 & -0.07 & -0.04 & -0.01 & 0.13 & -0.628 & 1.51 & -0.22 & -1.79 & $\mathbf{0 . 1 6}$ & -0.92 \\
\hline
\end{tabular}

$\mathrm{R}$ (Residual Effect) $=0.025$

DS $=$ Days to $100 \%$ sprouting, $\mathrm{DB}=$ Days to $50 \%$ bolting, $\mathrm{LS}=$ Length of stalk, FP =Percent of fertile pollen, $\mathrm{UD}=$ Umbel diameter, NSP $=$ Number of seeds per plant, $\mathrm{SW}=100$-seed weight, $\mathrm{NFU}=$ Number of flowers per umbel, NSU $=$ Number of seeds per umbel, NFSU $=$ Number of filled seeds per umbel, NUSU $=$ Number of unfilled seeds per umbel and SYU $=$ seed yield per umbel. 
These findings suggested that for breeding program, emphasis should be given on these characters having direct effect on seed yield such as number of filled seeds per umbel (1.87), number of flowers per umbel (1.52) and 100 seed weight $(0.74 \mathrm{~g})$. Insignificant negative correlation between days to $100 \%$ sprouting and seed yield was the contribution of positive indirect and direct effect. Similar results were also reported by Mohanty (2001) for bulb yield of onion. The residual effect of the present study was 0.025 indicating of the variability of seed yield per umbel was contributed mostly by the ten characters studied in the path analysis.

\section{REFERENCES}

Aliyu, U., M. D. Magaji. A. I. Yakubu and A. U. Dikko. 2007. Correlation and path coefficient analysis for some yield related traits in onion (Allium cepa L.). J. Plant Sci. 2 (3): 366-369.

Mc. Collum, G. D. 1976. Evaluation of Crop plants. Ed N.W. Simmonds, Longman, London and New York. pp. 186-190.

Mohanty, B. K. 2001. Genetic variability inter-relationship and path analysis in onion. J. Trop. Agric. 39 (1): 17-20.

Pooler, M. R and P. W. Simon. 1993. Characterization and classification of isozyme and morphological variation in a diverse collection of garlic clones. Euphytica. 68: 121-130.

Rahman M. A., M. A. Salam., A. S. M. H. Masum and S. S. Chowdhury. 2002. Correlation and path coefficient analysis in Onion (Allium cepa L.). J. Bio. Sci. 2(8): 531-532.

Singh, D. N., A. 1987. Tropical Crops (Monocotyledons). Longman Scientific and Technical, New York. p.41.

Singh, M. C., and R. S. Tiwari. 1995. Yield and quality attributes of garlic (Allium sativum L.) Accessions. Haryana J. Hort. Sci. 24: 46-49.

Uddin, M. M., A. Samad, M. R. Khan, S. Begum and M. A. Salam. 1985. Correlation and path analysis of yield and yield contributing characters in Brassica species, Bangladesh J. Agric. Res. 10: 71-75. 